\title{
Position Statement: Sharing of Clinical Research Data in Spinal Muscular Atrophy to Accelerate Research and Improve Outcomes for Patients
}

\author{
Hanns Lochmüller ${ }^{\mathrm{a}, *}$, David Evans ${ }^{\mathrm{b}}$, Wildon Farwell ${ }^{\mathrm{c}}$, Richard Finkel ${ }^{\mathrm{d}}$, Nathalie Goemans ${ }^{\mathrm{e}}$, \\ Mencia de Lemus ${ }^{\mathrm{f}, 1}$, Vitaliy Matyushenko ${ }^{\mathrm{g}, 1}$, Francesco Muntoni ${ }^{\mathrm{h}}$, Marie-Christine Ouillade ${ }^{\mathrm{i}, 1}$, \\ Inge Schwersenz ${ }^{\mathrm{j}, 1}$ and Petra Wilson ${ }^{\mathrm{k}}$ \\ ${ }^{a}$ Department of Neuropediatrics and Muscle Disorders, Medical Center - University of Freiburg, Faculty of \\ Medicine, Freiburg, Germany \\ ${ }^{\mathrm{b}}$ Data Science - Personalized Health Care, F. Hoffmann-La Roche, Basel, Switzerland \\ ${ }^{\mathrm{c}}$ Biogen, Cambridge, MA, USA \\ ${ }^{\mathrm{d}}$ Department of Pediatrics, Division of Neurology, Nemours Children's Hospital, Orlando, USA \\ ${ }^{\mathrm{e}}$ Department of Pediatrics and Child Neurology, University Hospitals Leuven, Leuven, Belgium \\ ${ }^{\mathrm{f}}$ Fundación Atrofia Muscular Espinal, FundAME, Madrid, Spain \\ ${ }^{\mathrm{g}}$ Children with Spinal Muscular Atropy, Charitable Foundation, Kharkiv, Ukraine \\ ${ }^{\mathrm{h}}$ University College London Great Ormond Institute of Child Health, London, UK; and NIHR Great Ormond \\ Street Hospital Biomedical Research Centre, London UK \\ ${ }^{\mathrm{i}}$ AFM-Telethon, Evry, Ile-de-France, France \\ ${ }^{\mathrm{j}}$ Deutsche Gesellschaft für Muskelkranke e.V., Freiburg, Germany \\ ${ }^{\mathrm{k}}$ Health Connect Partners, Brussels, Belgium \\ ${ }^{1}$ SMA Europe, Chipping Campden, UK
}

Recent years have seen increasing clinical research activities in spinal muscular atrophy (SMA), involving patients, their families, clinicians, researchers, regulators and industry [1-3]. This has led to unprecedented advancements in understanding of genetic determinants of severity and prognosis, the natural history, outcome measures, and most importantly first marketed therapies [4-8]. However, many patients with SMA do not benefit yet from effective treatments or show limited clinical response or impact on their quality of life.

\footnotetext{
*Correspondence to: Hanns Lochmüller, MD, FAAN, Department of Neuropediatrics and Muscle Disorders, Medical Center-University of Freiburg, Mathildenstr. 179160 Freiburg Germany. E-mail: Hanns.Lochmuller@gmail.com.
}

A major barrier to carry out further clinical research is the relatively low incidence and prevalence of SMA [9, 10], considered a Rare Disorder (RD) covered by Orphan Drug Regulations in most jurisdictions. Many of the remaining challenges are not specific to SMA, but common across different RDs, across research domains and are linked to the unavailability of data of sufficient quality. Clinical trial in RDs considered as pivotal frequently do not cover the entire disease spectrum such as severity or age range. These gaps in knowledge lead to marketing approvals granted under the condition for stringent and comprehensive collection of post marketing, reallife outcome data.

This is not only due to the scarcity of data, but also to the lack of options to reuse data that does 
exist. This may include options to take advantage of existing natural history data; and concerns related to the accuracy of the data collected. Therefore, international organizations involved in RD research have endorsed mechanisms and standards enabling data sharing [11-13], including the international charter of principles for sharing bio-specimens and data and the FAIR principles for data (findable, accessible, interoperable, reusable). Important issues to address are privacy protection issues, lack of infrastructure for data sharing, lack of standards and interoperability, reluctance to share unpublished data, lack of capacity to analyse large amounts of data, and challenges of linking different datasets in different places. The benefits of sharing data and samples in RDs are: overcoming the "rare disease problem" in clinical research, eg cohort size, powering trials and finding confirmatory cases, reducing costs and duplication of effort, facilitating validation of results and enabling engagement with experts and the patient community.

A recent workshop with panellists from patient organizations, academia and industry discussed the challenges and benefits of data sharing in SMA clinical research at the international conference of SMA Europe in Krakow (full workshop report in the supplementary material). The discussion brought several activities to light where international collaboration, close interactions between different stakeholders and data sharing, have contributed to the recent successes in SMA clinical research, including the transnational collaboration of patient organizations in SMA Europe, multi-centric studies into natural history and outcome measures, global trial readiness through registries and biobanks (TREAT-NMD, 14), and commercially sponsored multinational trials. Moreover, new opportunities and challenges in SMA research were identified, that may benefit or have an impact on data sharing, including patient-reported outcome measures, trials without placebo groups, real-world outcome and safety of marketed products, and the changing legal environment in European data protection (GDPR, General Data Protection Regulation).

The following statements were made during the workshop and were broadly agreed to by the authors:

1. SMA patients, families and patient organizations want to play a critical role in SMA research, not only through participation and dissemination, but through governance and design of studies and outcome measures, as well as access and use of research data.
2. Data capture in SMA should wherever possible follow the IRDiRC-recognized "FAIR Guiding Principles" in order to make the collected data Findable, Accessible, Interoperable and Reusable and thus maximise their utility for research.

3. Disease-specific registries are recommended by regulatory agencies, supported by all stakeholders, and favoured over product-specific registries to avoid fragmentation, save resources and to allow meaningful analysis across both treated and untreated SMA patients.

4. Real-life (post-marketing) outcome data capture is warranted due to regulatory and payer commitments in SMA, and requires a high degree of transnational collaboration and standardization (eg data items, data capture, IT, monitoring, analysis) to ensure reporting at the required detail, quality and speed.

5. Companies sponsoring clinical trials in SMA are encouraged to share their placebo arm data through an agreed mechanism allowing access to the data by other investigators both from the academic and the commercial sector, in order to limit or avoid placebo groups in future clinical trials as recommended by the recent EMA workshop [15].

6. Data collections from natural history studies, clinical trials and patient registries in SMA are precious resources that involve extensive effort and investment from academics, pharmaceutical companies and most of all the patients themselves. Benefits derived from these collections must be shared amongst contributing stakeholders and the principles of equality of access, benefit sharing and return of results should at all times be considered.

7. The GDPR in Europe coming into effect in May 2018 does not prevent data sharing in clinical SMA research, but provides legislation that is less divergent amongst different European member states than current frameworks.

Similar principles and recommendations might be applicable to other areas of SMA research, such as standards of care, biomarkers and burden of illness, but were not covered in the workshop. Similarly, data sharing in preclinical research - beyond the publication in peer-reviewed scientific journals - is very pertinent and reviewed elsewhere. 


\section{DISCLAIMER}

This statement reflects the personal opinion of the authors, but cannot be seen as binding to the organisations the authors are affiliated with. It aims to reflect and summarize a multi-stakeholder discussion that took place at the SMA Europe conference in Krakow in January 2018.

\section{ACKNOWLEDGMENTS}

We wish to thank the organizers of the SMA Europe conference in Krakow for supporting the workshop, workshop participants for their contributions to the general discussion and Joanne Bullivant (Newcastle, UK) for taking notes.

\section{SUPPLEMENTARY MATERIAL}

The supplementary material is available in the electronic version of this article: http://dx.doi.org/ 10.3233/JND-180325.

\section{REFERENCES}

[1] Scoto M, Finkel RS, Mercuri E, Muntoni F. Therapeutic approaches for spinal muscular atrophy (SMA). Gene Ther. 2017;24(9):514-9.

[2] Groen EJN, Talbot K, Gillingwater TH. Advances in therapy for spinal muscular atrophy: Promises and challenges. Nat Rev Neurol. 2018;14(4):214-24.

[3] Pechmann A, Kirschner J. Diagnosis and New Treatment Avenues in Spinal Muscular Atrophy. Neuropediatrics. 2017;48(4):273-81.

[4] Rouault F, Christie-Brown V, Broekgaarden R, Gusset N, Henderson D, Marczuk P, Schwersenz I, Bellis G, Cottet C. Disease impact on general well-being and therapeutic expectations of European Type II and Type III spinal muscular atrophy patients. Neuromuscul Disord. 2017;27(5):428-38.

[5] Glanzman AM, McDermott MP, Montes J, Martens WB, Flickinger J, Riley S, Quigley J, Dunaway S, O'Hagen J, Deng L, Chung WK, Tawil R, Darras BT, Yang M, Sproule D, De Vivo DC, Kaufmann P, Finkel RS; Pediatric Neuromuscular Clinical Research Network for Spinal Muscular Atrophy (PNCR); Muscle Study Group (MSG). Validation of the Children's Hospital of Philadelphia Infant Test of Neuromuscular Disorders (CHOP INTEND). Pediatr Phys Ther. 2011;23(4):322-6.
[6] Mercuri E, Darras BT, Chiriboga CA, Day JW, Campbell C, Connolly AM, Iannaccone ST, Kirschner J, Kuntz NL, Saito K, Shieh PB, Tulinius M, Mazzone ES, Montes J, Bishop KM, Yang Q, Foster R, Gheuens S, Bennett CF, Farwell W, Schneider E, De Vivo DC, Finkel RS; CHERISH Study Group. Nusinersen versus Sham Control in Later-Onset Spinal Muscular Atrophy. N Engl J Med. 2018;378(7):62535 .

[7] Finkel RS, Mercuri E, Darras BT, Connolly AM, Kuntz NL, Kirschner J, Chiriboga CA, Saito K, Servais L, Tizzano E, Topaloglu H, Tulinius M, Montes J, Glanzman AM, Bishop K, Zhong ZJ, Gheuens S, Bennett CF, Schneider E, Farwell W, De Vivo DC; ENDEAR Study Group. Nusinersen versus Sham Control in Infantile-Onset Spinal Muscular Atrophy. N Engl J Med. 2017;377(18):1723-32.

[8] Bertini E, Dessaud E, Mercuri E, Muntoni F, Kirschner J, Reid C, Lusakowska A, Comi GP, Cuisset JM, Abitbol JL, Scherrer B, Ducray PS, Buchbjerg J, Vianna E, van der Pol WL, Vuillerot C, Blaettler T, Fontoura P; Olesoxime SMA Phase 2 Study Investigators. Safety and efficacy of olesoxime in patients with type 2 or nonambulatory type 3 spinal muscular atrophy: A randomised, double-blind, placebo-controlled phase 2 trial. Lancet Neurol. 2017;16(7):513-22.

[9] Verhaart IEC, Robertson A, Leary R, McMacken G, König K, Kirschner J, Jones CC, Cook SF, Lochmüller H. A multisource approach to determine SMA incidence and research ready population. J Neurol. 2017;264(7):1465-73.

[10] Verhaart IEC, Robertson A, Wilson IJ, Aartsma-Rus A, Cameron S, Jones CC, Cook SF, Lochmüller H. Prevalence, incidence and carrier frequency of 5q-linked spinal muscular atrophy - a literature review. Orphanet J Rare Dis. 2017;12(1):124.

[11] Mascalzoni D, Dove ES, Rubinstein Y, Dawkins HJ, Kole A, McCormack P, Woods S, Riess O, Schaefer F, Lochmüller $\mathrm{H}$, Knoppers BM, Hansson M. International Charter of principles for sharing bio-specimens and data. Eur J Hum Genet. 2015;23(6):721-8.

[12] Lochmüller H, Torrent I Farnell J, Le Cam Y, Jonker AH, Lau LP, Baynam G, Kaufmann P, Dawkins HJ, Lasko P, Austin CP, Boycott KM; IRDiRC Consortium Assembly. The International Rare Diseases Research Consortium: Policies and Guidelines to maximize impact. Eur J Hum Genet. 2017;25(12):1293-302.

[13] Lochmüller H, Le Cam Y, Jonker AH, Lau LP, Baynam G, Kaufmann P, Lasko P, Dawkins HJ, Austin CP, Boycott KM. 'IRDiRC Recognized Resources': A new mechanism to support scientists to conduct efficient, high-quality research for rare diseases. Eur J Hum Genet. 2017;25(2):162-5.

[14] Thompson R, Robertson A, Lochmüller H. Natural History, Trial Readiness and Gene Discovery: Advances in Patient Registries for Neuromuscular Disease. Adv Exp Med Biol. 2017;1031:97-124.

[15] http://www.ema.europa.eu/ema/index.jsp?curl=pages/news _and_events/news/2016/11/news_detail_002633.jsp\&mid= WC0b01ac058004d5c1; accessed March 26, 2018. 